\title{
O TRABALHO EXPERIMENTAL NO ENSINO DE QUÍMICA
}

\author{
Soraia Freaza Lôbo \\ Departamento de Química Geral e Inorgânica, Universidade Federal da Bahia, 40170-290 Salvador - BA, Brasil
}

Recebido em 3/5/11; aceito em 19/8/11; publicado na web em 30/9/11

\begin{abstract}
THE EXPERIMENTAL WORK IN THE CHEMISTRY TEACHING. This article deals with conceptions of the experimental work in the Chemistry teaching, developed among teachers and students. The research was carried out using qualitative methodology, based on Gaston Bachelard's thoughts. The results showed dispersion of conceptions among both students and teachers. This dispersion, interpreted as a profile of conceptions, was discussed based on the notions of Bachelard's epistemological profile and Mortimer's conceptual profile. This work points out the need to rethinking and finding new directions for experimental activities in the training courses for Chemistry teachers, in order to meet Chemistry educators' social goals.
\end{abstract}

Keywords: experimental work; chemistry teaching.

\section{INTRODUÇÃO}

Há, praticamente, um consenso em que o trabalho experimental se constitui em um poderoso recurso didático para o ensino de ciências. Apesar disso, ainda são poucos os trabalhos dedicados a este tema e, na maior parte das vezes, referem-se ao uso do experimento no nível médio de ensino. ${ }^{1,2}$

Uma discussão muito apropriada sobre a função do trabalho experimental no ensino de ciências foi feita por Hodson. ${ }^{3}$ Neste trabalho o autor chama atenção para três aspectos: 1 - a proposta do experimento; 2- o procedimento experimental; 3- os resultados obtidos. Para ele, cada um destes aspectos tem diferentes funções pedagógicas. A proposta do experimento é importante no ensino e compreensão do método científico; o procedimento experimental pode aumentar a motivação dos alunos e ensinar-lhes as tarefas manipulativas e, a discussão dos resultados contribui para a aprendizagem dos conceitos científicos. Em trabalho posterior, este mesmo autor chama atenção sobre a necessidade de redefinição e reorientação do trabalho prático para contemplar três principais aspectos da educação científica: aprender ciência, aprender sobre a ciência e fazer ciência. ${ }^{4}$ Segundo este autor, aprender ciência significa se apropriar das suas teorias, princípios e modelos; aprender sobre a ciência requer o conhecimento do seu processo de produção, dos aspectos metodológicos e de validação de suas teorias; fazer ciência, por sua vez, corresponde a desenvolver no aprendiz a prática investigativa, própria da atividade científica.

Os três aspectos citados acima são de fundamental importância no ensino superior de Química e devem ser cuidadosamente articulados para atender às diferentes finalidades sociais da formação profissional em Química, quais sejam a de formação de professores e de pesquisadores químicos. No entanto, para os dois casos, defendo que estes aspectos devam estar filosófica e pedagogicamente antenados com as questões contemporâneas relativas à educação científica.

Nos últimos anos tem havido um crescente interesse, entre pesquisadores que trabalham com o ensino de ciências, em focalizar a realidade da sala de aula, em especial as relações entre as concepções de professores e alunos, bem como aquelas entre professores e as suas práticas docentes. Trabalhos como os de Harres ${ }^{5}$ e McComas e Almazroa ${ }^{6}$ mostram esta relação e apontam para a necessidade de uma maior articulação entre o que é planejado no currículo e o que é,

e-mail: soraia@ufba.br efetivamente, concretizado. Esta articulação é necessária pois, como indicam algumas pesquisas, os professores exercem uma influência marcante no processo de implementação do currículo em sala de aula..$^{7-9}$ Neste processo, eles não implementam o currículo da mesma forma que ele foi planejado para ser implementado. Os professores tendem a priorizar aspectos do currículo que estão de acordo com o seu sistema de crenças, valores e concepções, rejeitando aqueles que enfatizam valores diferentes dos seus. ${ }^{9}$ Portanto, é fundamental que, nas discussões sobre as formações inicial e continuada de professores e sobre o planejamento e implementação de novos currículos nas escolas, as questões relativas às crenças e concepções epistemológicas relativas à ciência ensinada e a influência que estas concepções têm sobre as práticas pedagógicas sejam problematizadas, visando superar práticas irrefletidas, próprias do senso comum.

Na discussão sobre a reforma curricular dos cursos de Química da UFBA, iniciada em 1999, o trabalho experimental como um recurso didático no currículo foi muito pouco questionado. Apesar de haver um consenso, entre professores e alunos, que este é um importante recurso didático para o ensino de Química, percebe-se um descontentamento com esta atividade curricular e, em alguns casos, constata-se que ela não tem atingido os objetivos pretendidos durante o seu planejamento.

Ao serem questionados sobre os problemas mais comumente encontrados nas aulas, os professores citam: dificuldades de manipulação dos materiais do laboratório pelos alunos; baixo nível de compreensão dos fenômenos pelos discentes; tempo inadequado para a realização das atividades; dificuldade que os alunos têm de relacionar teoria e prática, conhecimentos teóricos insuficientes para o acompanhamento das aulas pelos alunos, entre outros. Apesar disso, as iniciativas de superação destes obstáculos têm esbarrado em dificuldades, em parte pelo grande engessamento do currículo e, ainda, pela quase ausência de questionamentos que poderiam resultar em propostas de reorientação das aulas práticas, como: que concepção pedagógica deve orientar o experimento? Qual a proposta do experimento? O que se quer enfatizar: a aprendizagem dos conceitos, a adequada manipulação dos equipamentos pelos alunos? Que conteúdos são relevantes? Qual o seu contexto de aplicação? Estas e outras questões são importantes para que as aulas experimentais tenham, realmente, uma função pedagógica no ensino de Química.

A pesquisa aqui relatada teve início durante o período de reforma curricular dos cursos da UFBA, o que possibilitou o contexto adequado para a percepção dos valores, crenças e concepções presentes, 
explícita ou implicitamente na comunidade, em especial, entre professores e alunos do curso. Essas crenças e concepções conformam códigos culturais, no sentido proposto por Bernstein ${ }^{10} \mathrm{e}$, muitas vezes, constituem verdadeiros obstáculos a atitudes inovadoras no sentido de mudança da realidade.

Este trabalho teve como objetivo conhecer e explicitar as concepções de professores e alunos do curso sobre a atividade experimental e o seu uso como recurso didático no ensino de Química. Nesta perspectiva, partiu-se do pressuposto de que estas concepções, de natureza pedagógica, são afetadas pelas posturas epistemológicas dos professores e alunos e contribuem para orientar as práticas docentes, com reflexos para o ensino e a formação do professor de Química.

\section{RESULTADOS E DISCUSSÃO}

A pesquisa foi realizada utilizando-se metodologia qualitativa e os dados foram levantados, via os seguintes instrumentos: questionários, entrevistas semiestruturadas, depoimentos e observação participante.

Foram selecionados 10 professores e 10 alunos dos cursos de Química sendo que, entre estes, 7 são alunos do curso de licenciatura e 3 do bacharelado. Os professores foram selecionados em função das disciplinas que ministravam. A seleção destas obedeceu aos seguintes critérios: disciplinas de caráter obrigatório para o curso de licenciatura; disciplinas que contemplassem as diversas áreas da Química: Química Inorgânica, Química Orgânica, Físico-Química e Química Analítica e aquelas com aulas de laboratório.

Os depoimentos e as entrevistas semiestruturadas foram gravadas e transcritas para a análise do conteúdo das mensagens. Este processo consistiu em interpretar as falas dos entrevistados e perceber os pontos relevantes que permitissem explicitar as suas concepções sobre o trabalho experimental no ensino de Química. Para isso, os textos resultantes da transcrição dos depoimentos e entrevistas foram desconstruídos e submetidos a um processo de categorização. ${ }^{11}$

Os processos de coleta e análise dos dados foram orientados por referenciais metodológicos, ${ }^{12,13}$ tendo como referencial epistemológico o pensamento do filósofo francês Gaston Bachelard.

O pensamento dos alunos sobre o trabalho experimental e sobre o seu uso como recurso didático para o ensino de Química pode ser apreendido dos seguintes trechos de falas (Unidades de Significado):

\begin{abstract}
"Acho que o laboratório é o lugar de observação, onde ele estuda o concreto. Depois que ele estuda o concreto, aí sim pode-se chegar à teoria e que isso deve ser feito na sala de aula, separado".

"O laboratório tem a função de mostrar o que a gente tinha visto na teoria. Mostrar que aquilo ali tem aplicação. Trazer para a realidade aquilo que a gente viu”.

"A função da aula de laboratório é motivar o interesse do aluno".

"Em relação à aula prática acho que primeiro temos que ver a teoria. A aula prática solidifica o que está sendo dado na teoria".

"Eu acho que o laboratório tem sim essa função de observar, cor, textura, coisas que você só vai aprender vendo. Além da observação também tem que ter um relato escrito”.
\end{abstract}

Do processo de categorização, citado anteriormente, foram obtidos Conceitos Gerais (CG) que representam e sintetizam as ideias gerais veiculadas por cada Unidade de Significado.

Na Tabela 1 são apresentados os Conceitos Gerais para os alunos. Nesta tabela, observa-se uma variedade de visões sobre o trabalho experimental. Para eles, o laboratório é um lugar para se fazer observações, dar apoio à aula teórica, espaço para reflexão, desenvolver habilidades como observação e manipulação, ilustrar situações do cotidiano, aplicar e comprovar teorias, identificar substâncias e relacionar a teoria à prática.

Tabela 1. Conceitos gerais dos alunos sobre o trabalho experimental

\begin{tabular}{cl}
\hline Entrevistado & Conceitos gerais \\
\hline A1 & $\begin{array}{l}\text { Comprovação de teorias; aplicação de teorias; dar habili- } \\
\text { dade ao aluno; despertar a curiosidade do aluno; ver a coisa } \\
\text { funcionando. }\end{array}$ \\
A2 & $\begin{array}{l}\text { Fazer observaçães e chegar a uma teoria; ilustração de casos } \\
\text { particulares; quebrar a monotonia da sala de aula; estudar } \\
\text { o concreto. }\end{array}$ \\
A3 & $\begin{array}{l}\text { Apoio à aula teórica; observar questionando os alunos; ob- } \\
\text { servação das propriedades. }\end{array}$ \\
A4 & $\begin{array}{l}\text { Aliar a teoria à prática; desenvolver habilidades práticas. } \\
\text { A5 }\end{array}$ \\
Identificação de substâncias; aplicação das coisas do dia a dia. \\
A7 & $\begin{array}{l}\text { Despertar o interesse do aluno. } \\
\text { Solidificar o conhecimento (teórico); comprovação dos fatos; } \\
\text { aplicação de teorias. }\end{array}$ \\
A8 & Familiarizar com os equipamentos \\
A9 & $\begin{array}{l}\text { Trabalho de investigação; espaço para observação e ma- } \\
\text { nipulação. }\end{array}$ \\
A10 & Relacionar teoria e prática; relação com o cotidiano.
\end{tabular}

Alguns aspectos podem ser sinalizados, a partir desta tabela: o papel central da observação no trabalho experimental; a ideia de que, a partir da observação do fenômeno, se pode chegar à teoria; a importância da relação entre a teoria e a prática.

O papel central da observação no trabalho prático pode ser apreendido diretamente das falas dos alunos A1, A2, A3 e A9. Embora o aluno $\mathrm{A} 5$ não tenha feito referência direta à observação, o seu discurso revelou uma crença na atividade experimental e na observação dos fenômenos, como pontos de partida para o estudo da Química.

O status dado à observação e ao uso dos órgãos do sentido na produção do conhecimento científico constitui o princípio do empirismo, estabelecido desde Aristóteles e largamente difundido durante todo o século XVII até o século XIX.

A ideia de que é necessária uma prova empírica para a confirmação de teorias reforça uma postura epistemológica que tem sido hoje muito criticada por filósofos da ciência e educadores das disciplinas científicas. Entre estes, Mortimer ${ }^{14}$ chama atenção para o fato de que na Química, embora os fatos e fenômenos estejam associados à empiria, a maior parte deles não foi obtida por uma doutrina empirista, mas através de formulações teóricas, como foram os casos das hipóteses de Lavoisier, para explicar a combustão, e a de Dalton, na proposição do seu modelo atômico.

A concepção empirista está associada à crença de que o conhecimento científico é um conhecimento verdadeiro, inquestionável e, portanto, o experimento deve corroborar os enunciados teóricos. Os resultados mostrados, especialmente para os alunos A1, A3 e A7, na Tabela 1, parecem estar associados a esta postura.

Ainda na Tabela 1, observa-se, para o aluno A2, uma tendência a uma concepção epistemológica empirista-indutivista, ao afirmar que o trabalho experimental tem a função de "fazer observações e chegar a uma teoria". A ideia de que o conhecimento científico é obtido diretamente dos resultados experimentais está, ainda, muito presente no ensino de ciências e entre professores e alunos de Química. ${ }^{11}$

A seguir, pode-se constatar uma postura empirista-indutivista de ciência, através dos seguintes trechos de falas (Unidades de Significado) de dois alunos: 
"Ciência é aquela ferramenta de investigação, de observação de determinados fenômenos. Então, a partir dali, daquela observação, daquele estudo, você pode estabelecer leis que regem aquele fenômeno, em qualquer ciência".

"Quando se fala que Química é uma ciência experimental, as teorias da Química são em função dos experimentos. A partir dos experimentos, o cientista tira conclusões”.

A perspectiva epistemológica de cunho empirista-indutivista está, muitas vezes, implícita no ensino de ciências, nos materiais didáticos, no discurso e na prática do professor. A defesa da observação como ponto de partida para a construção do conhecimento, feita pelos empiristas clássicos, confere um status privilegiado à observação. O sucesso da teoria vai depender do processo de obtenção dos dados e, por isto, estes devem ser obtidos de forma cuidadosa e neutra. No entanto, não se quer dizer aqui que a observação não seja importante no processo de produção do conhecimento científico e, também, no ensino de ciências. O problema reside quando ela está dissociada de um referencial teórico que oriente a observação dos fenômenos e quando é utilizada numa situação de ensino sem uma problematização, sem uma interrogação que suscite o levantamento de hipóteses e que, por sua vez, dê origem a novas observações e experiências, num movimento dinâmico e criativo, característico do empreendimento científico.

Na sua crítica ao empirismo e às primeiras impressões, no trato das questões científicas, Bachelard defende que o pensamento empírico pressupõe um conjunto de argumentos pois, diante do real, de todo o seu mistério, não se pode ser ingênuo e anular, imediatamente, todas as pré-concepções ou conhecimentos habituais. Para ele, a ciência opõe-se à opinião, ao dado imediato, àquilo que aparece aos sentidos, de forma que ela é o primeiro obstáculo epistemológico a ser superado. Diante do real, não se deve aceitar a sedução do pensamento mais simples, mais evidente. É necessário questionar o conhecimento, problematizá-lo, pois todo conhecimento é resposta a uma pergunta. Para ele: "se não há pergunta, não pode haver conhecimento científico. Nada é evidente. Nada é gratuito. Tudo é construído". ${ }^{15}$

A relação entre teoria e prática, como uma das funções do trabalho experimental, foi apontada pelos alunos A4 e A10. Apesar de constituir um importante aspecto no ensino de Química, ele foi mais enfatizado por professores que por alunos e, por isso, será discutido posteriormente, quando serão analisados os resultados obtidos para os docentes.

Assim como para os alunos, o pensamento dos professores sobre o trabalho experimental e o seu uso como recurso didático para o ensino de Química, pode ser apreendido dos seguintes trechos de falas:

\section{"Comprovar experimentalmente fatos teóricos tidos como lei”. \\ "Permitir ao aluno aplicar a teoria à prática". \\ "Propiciar aos alunos o acesso aos equipamentos e técni- cas". \\ "Reforçar o aprendizado obtido nas aulas teóricas". \\ "Função fundamental para a construção de propostas que levam às leis e teorias". \\ "Formação de conceitos".}

Assim como descrito para os alunos, o processo de categorização, a partir das Unidades de Significado, extraídas das falas dos professores, resultou nos Conceitos Gerais apresentadas na Tabela 2.

Estes resultados mostram uma diversidade de concepções dos professores sobre o trabalho experimental no ensino de Química. Observa-se uma preocupação em utilizar a aula de laboratório para a "comprovação de teorias" (PQ1); "reconstruir conhecimentos teó-
Tabela 2. Conceitos gerais dos professores sobre o trabalho experimental

\begin{tabular}{cl}
\hline Professor & Conceitos gerais \\
\hline PQ1 & $\begin{array}{l}\text { Comprovação de teorias; uma forma de construção de conhe- } \\
\text { cimento. }\end{array}$ \\
PQ2 & Estimular o aprendizado através do fazer. \\
PQ3 & Permitir ao aluno aplicar a teoria à prática. \\
PQ4 & Construir conhecimento; aplicar conhecimentos. \\
PQ5 & $\begin{array}{l}\text { Acesso a equipamentos e técnicas; reconstruir conhecimentos } \\
\text { teóricos; "ler" criticamente os experimentos. }\end{array}$ \\
PQ6 & $\begin{array}{l}\text { Exemplificar; introduzir os alunos na investigação; desenvolver } \\
\text { habilidades técnicas; formação de conceitos. }\end{array}$ \\
PQ7 & $\begin{array}{l}\text { Reforçar a teoria; desenvolver habilidades técnicas. } \\
\text { PQ8 }\end{array}$ \\
Desenvolver habilidades técnicas; relacionar a teoria à prática. \\
PQ9 & $\begin{array}{l}\text { Acesso a equipamentos; comprovação de teorias; correlação } \\
\text { entre teoria e prática; fixação do assunto teórico. }\end{array}$ \\
PQ10 & $\begin{array}{l}\text { Ensinar conceitos químicos; desenvolver habilidades técnicas; } \\
\text { desenvolver o raciocínio científico. }\end{array}$ \\
\hline
\end{tabular}

ricos" (PQ5); "reforçar a teoria" (PQ7); “comprovação de teorias" e "fixação do assunto teórico" (PQ9). Nestes casos, o trabalho experimental é um recurso para a confirmação/consolidação das teorias científicas da Química, evidenciando a centralidade dos aspectos teórico-conceituais sobre o fenomenológico, na mediação das aulas.

A Tabela 2 mostra, ainda, a preocupação dos professores em utilizar o laboratório como um recurso para relacionar teoria e prática. Apesar disso, esta relação tem se mostrado problemática, de modo que, de modo geral, a aula de laboratório tem deixado de cumprir uma importante função pedagógica, qual seja a de contribuir para estabelecer relações entre os níveis teórico-conceitual e fenomenológico do conhecimento químico, de fundamental importância para a compreensão da estrutura da ciência Química.

Os dois níveis do conhecimento químico, citados acima, além do nível representacional, devem ser constantemente inter-relacionados no processo de mediação didática do professor, para que o aluno perceba a complexidade que é a produção e socialização desse conhecimento. Este processo deve ser cuidadosamente planejado, caso se deseje enfatizar a aprendizagem dos conceitos químicos (produtos da ciência química) ou do seu processo de produção (conhecimento sobre a Química).

A observação das aulas de laboratório revelou a dificuldade que os alunos têm em estabelecer relações entre estes três níveis do conhecimento químico. Segundo depoimentos de alguns professores, o aluno não consegue relacionar a teoria à prática, devido à sua "falta de base" do ensino médio. Para a maior parte dos docentes entrevistados, a teoria é considerada um pré-requisito importante para a atividade experimental e, com base nesta crença, a organização das aulas é feita de modo a garantir, na medida do possível, a realização de aulas de laboratório logo após ou, pelo menos, no mesmo período que as aulas teóricas sobre o mesmo tema.

A dicotomia teoria/prática tem sido um elemento presente na estrutura curricular do curso, tanto entre as disciplinas específicas de Química, como entre as pedagógicas. Esta estrutura é resultante do modelo da racionalidade técnica predominante nos currículos da formação de professores no Brasil. Com a última reforma curricular, que resultou na implementação do novo currículo, em 2007, a criação de novos componentes curriculares teve como principal objetivo promover uma maior articulação entre disciplinas de conteúdo específico de Química e disciplinas pedagógicas. Entre estes componentes, $\mathrm{O}$ Experimento no Ensino de Química tem o objetivo de utilizar o tra- 
balho experimental como recurso didático, enfatizando processos de mediação que têm, como eixos orientadores, a filosofia da ciência, o conhecimento químico, a prática científica em Química e a articulação entre estes aspectos e a didática da Química.

Os Conceitos Gerais, mostrados nas Tabelas 1 e 2, foram categorizados com o objetivo de se conhecer as concepções de alunos e professores sobre o trabalho experimental no ensino de Química. As concepções são aqui entendidas como entidades abstratas correspondentes à "percepção, criação, imaginação ou imagem de uma coisa na mente". ${ }^{11}$ São entidades ou conceitos que, na visão do pesquisador, traduzem o pensamento dos sujeitos pesquisados. Estas Concepções são apresentadas nas Tabelas 3 e 4, juntamente com as frequências com que elas aparecem entre alunos e professores.

Para os alunos, as Concepções sobre o trabalho experimental, resultantes do processo de categorização dos conceitos gerais, foram: A - comprovação de teorias; B - aplicação de teorias; C - observação de propriedades e fenômenos; D - desenvolvimento de habilidades; E - relação teoria-prática; F - estudo de coisas concretas; G - recurso para motivar o aluno; $\mathrm{H}$ - trabalho de pesquisa.

Tabela 3. Frequências de concepções dos alunos sobre o trabalho experimental

\begin{tabular}{lllllllll}
\hline \multirow{7}{*}{ Aluno } & \multicolumn{7}{c}{ Concepções } \\
\cline { 2 - 9 } & A & B & C & D & E & F & G & H \\
\hline A1 & + & + & & + & & & + & \\
A2 & & & + & & & + & + & \\
A3 & & & + & & + & & & \\
A4 & & & & + & + & & & \\
A5 & & & & & & + & & \\
A6 & & & & & & & + & \\
A7 & + & + & & & + & & & \\
A8 & & & & + & & & & \\
A9 & & & & & & & & \\
A10 & & & & & & & & \\
\hline
\end{tabular}

Para os professores, as Concepções sobre o trabalho experimental foram: A - comprovação de teorias; B - construção de conhecimento; C - aplicar teoria à prática; D - estimular o aprendizado através do fazer; E - acesso a equipamentos e técnicas; F - ler criticamente os experimentos; $\mathrm{G}$ - reconstruir conhecimentos; $\mathrm{H}$ - introduzir os alunos na investigação; I - desenvolver habilidades técnicas; J - reforçar a teoria; K - ensinar conceitos; L - desenvolver o raciocínio científico.
Os resultados apresentados nas Tabelas 3 e 4 mostram uma grande dispersão de concepções sobre o trabalho experimental no ensino de Química, tanto para o conjunto de professores e alunos, quanto para cada professor e aluno, individualmente.

A ideia de trabalhar com o perfil de concepções foi inspirada nas ideias de Bachelard, em especial na sua noção de perfil epistemológico,${ }^{16}$ e na noção de perfil conceitual, de Mortimer. ${ }^{17}$ Para Bachelard, cada conceito científico necessitou de perspectivas filosóficas diferenciadas, como o realismo ingênuo, postura epistemológica mais próxima do senso comum; o empirismo claro e positivista, que se detém na experiência imediata, na medida; o racionalismo clássico, postura epistemológica da mecânica clássica, até chegar ao racionalismo dialético da ciência contemporânea, o racionalismo da mecânica quântica, que, segundo ele, corresponde a uma perspectiva mais adequada para traduzir o estágio do desenvolvimento científico no início do século XX. Estas várias perspectivas se constituem, segundo ele, em uma dispersão filosófica e representa um espectro das ideias filosóficas de um conceito científico presentes em um dado momento histórico do seu desenvolvimento e "guarda as marcas dos obstáculos que uma cultura teve que superar". ${ }^{16}$

Assim como ao longo da história do pensamento científico várias concepções epistemológicas conviveram com razoável harmonia, também um determinado sujeito pode ter diferentes perspectivas filosóficas para um mesmo conceito científico, em função dos diferentes estágios de desenvolvimento do seu próprio conhecimento.

A dispersão de concepções apresentada nas Tabelas 3 e 4 representa as diferentes finalidades didáticas que o trabalho experimental deve ter, segundo os professores e alunos pesquisados. Neste sentido, estes resultados mostram um espectro de concepções que revelam pensamentos diferenciados em relação ao uso deste recurso didático no ensino de Química. Algumas destas concepções estão mais afinadas com as atuais tendências da educação científica, como as de letra H (Tabelas 3 e 4) e L (Tabela 4), que ao enfatizarem a investigação e o desenvolvimento do raciocínio científico precisariam ser melhor desenvolvidas nas aulas experimentais do curso de Química.

Apesar da dispersão apresentada nas Tabelas 3 e 4, pode-se observar que a utilização do trabalho experimental para o estabelecimento de relações entre teoria e prática aparece com maior frequência, em relação às demais. Nestas tabelas também é mostrado que o trabalho experimental deve ter a finalidade de comprovação e aplicação de teorias. Este resultado parece apontar para uma visão de relação teoria-prática no ensino de Química na qual a prática fica a serviço da comprovação de teorias pré-estabelecidas. Nesta perspectiva, embora professores e alunos tenham apontado outras finalidades importantes para a aula de laboratório, como o

Tabela 4. Frequências de concepções dos professores sobre o trabalho experimental

\begin{tabular}{|c|c|c|c|c|c|c|c|c|c|c|c|c|}
\hline \multirow{2}{*}{ Professor } & \multicolumn{12}{|c|}{ Concepções } \\
\hline & A & B & $\mathrm{C}$ & D & $\mathrm{E}$ & $\mathrm{F}$ & $\mathrm{G}$ & $\mathrm{H}$ & I & $\mathrm{J}$ & $\mathrm{K}$ & $\mathrm{L}$ \\
\hline PQ1 & + & + & & & & & & & & & & \\
\hline PQ2 & & & & + & & & & & & & & \\
\hline PQ3 & & & + & & & & & & & & & \\
\hline PQ4 & & + & + & & & & & & & & & \\
\hline PQ5 & & & & & + & + & + & & & & & \\
\hline PQ6 & & & + & & & & & + & + & & + & \\
\hline PQ7 & & & & & & & & & + & + & & \\
\hline PQ8 & & & + & & & & & & + & & & \\
\hline PQ9 & + & & + & & + & & & & & + & & \\
\hline PQ10 & & & & & & & & & + & & + & + \\
\hline
\end{tabular}


desenvolvimento de habilidades técnicas, do raciocínio científico e, até mesmo, de atitudes investigativas (concepção H, Tabelas 3 e 4), uma visão ingênua de relação teoria - prática no ensino de Química compromete a compreensão sobre a ciência Química, um dos objetivos do trabalho experimental na formação de profissionais mais críticos em relação a esta ciência.

A ausência de um processo de mediação didática no trabalho experimental que contemple o aspecto aprender sobre a ciência, citado por Hodson ${ }^{4}$ e apresentado no início deste artigo, poderá consolidar crenças inadequadas sobre a ciência e a atividade científica, veiculadas pela mídia e por livros didáticos de ciências, como as apresentadas no trabalho de Kosminsky e Giordan. ${ }^{18}$ Para estes autores, o desconhecimento de professores e alunos sobre a ciência pode dificultar a compreensão dos fenômenos científicos e desmotivar os alunos no processo de aprendizagem. Além disso, o desconhecimento sobre a ciência ensinada contribui para a manutenção de obstáculos epistemológicos ainda presentes no ensino de Química, como o realismo ingênuo e o empirismo puro, que dificultam a compreensão da Química como uma ciência produto da interação empiria-razão. Para Bachelard, este dois elementos devem ser colocados juntos no pensamento científico, pois:

"um empirismo sem leis claras, sem leis coordenadas, sem leis dedutivas não pode ser pensado nem ensinado; um racionalismo sem provas palpáveis, sem aplicação à realidade imediata não pode convencer plenamente. $O$ valor de uma lei empírica prova-se fazendo dela a base de um raciocínio. Legitima-se um raciocínio fazendo dele a base de uma experiência. A ciência, soma de provas e de experiências, soma de regras e de leis, soma de evidências e de fatos, tem, pois, necessidade de uma filosofia com dois pólos". ${ }^{16}$

Ainda nas Tabelas 3 e 4, observa-se que a concepção de trabalho experimental como um recurso didático para a realização de atividades investigativas foi apontada por, apenas, um professor (PQ6) e um aluno (A9). Este resultado, além de mostrar uma coerência com as posturas epistemológicas explicitadas por professores e alunos do curso, ${ }^{11}$ aponta para a necessidade de se repensar e encontrar novas orientações para as atividades experimentais na formação de professores de Química, de modo a atender às finalidades apontadas por Hodson $^{4}$ e contextualizadas para a ciência Química, quais sejam as de aprender a Química, aprender sobre a Química e fazer Química.

\section{CONSIDERAÇÕES FINAIS}

Esta pesquisa mostrou que o trabalho experimental, embora largamente utilizado como recurso didático nos currículos dos cursos de Química, de modo geral não tem sido adequadamente orientado no sentido de propiciar uma maior compreensão sobre a ciência Química, sua estrutura e seu processo de produção.

A pesquisa aponta para a necessidade de se aprofundar o debate epistemológico entre professores e alunos do curso, visando superar obstáculos presentes no currículo, vinculados a concepções inadequadas da ciência Química e do conhecimento científico, como a empirista e empirista-indutivista, respectivamente. Estes obstáculos, por um lado, contribuem para uma prática pedagógica dissonante com as questões atuais da filosofia da ciência e da educação científica e, por outro, reforçam imagens inadequadas da ciência Química e da atividade científica, comprometendo a formação profissional, em especial, do licenciado.

O trabalho aqui relatado não está em sua forma acabada, desde que constitui uma entre as várias iniciativas que têm sido tomadas para a melhoria da formação docente em Química da nossa Universidade, a partir de um processo de constante pesquisa, reflexão e ação sobre o currículo da licenciatura. Entre estas iniciativas, está a criação da disciplina O Experimento no Ensino de Química, que tem a finalidade de aprofundar a discussão sobre a função do trabalho experimental no ensino de Química, no sentido de propor novos processos de mediação didática, filosófica e pedagogicamente orientados, visando uma maior e mais adequada compreensão da ciência Química.

\section{REFERÊNCIAS}

1. Borges, A. T.; Cad. Bras. Ens. Fis. 2002, 19, 3.

2. De Jong, O.; Enseñanza de las Ciências 1996, 14, 3.

3. Hodson, D.; Studies in Science Education 1985, 12, 43.

4. Hodson, D.; Science \& Education 1992, 1, 65.

5. Harres, J. B. S.; Educação 2000, 40.

6. McComas, W. F.; Almazroa, H.; Clough, M. P.; Science and Education 1998, 7, 6 .

7. Brickhouse, N. W.; J. Teacher Education 1990, 41, 3.

8. Gallagher, J. J.; Science Education 1991, 75, 1.

9. Cronin-Jones, L. L.; J. Research in Science Teaching 1991, $28,3$.

10. Bernstein, B.; Class, Codes and Control, Routledge and Kegan Paul: Londres, 1975.

11. Lôbo, S. F.; Tese de Doutorado, Universidade Federal da Bahia, Brasil, 2004.

12. Bardin, L.; Análise de Conteúdo, Edições 70: Lisboa, 1977.

13. Bodgan, R.; Biklen, S. K.; Investigação Qualitativa em Educação: uma introdução à teoria e aos métodos, Porto Editora: Porto, 1994.

14. Mortimer, E. F.; Quim. Nova 1992, 15, 245.

15. Bachelard, G.; A Formação do Espírito Científico: contribuição para uma psicanálise do conhecimento, Contraponto: Rio de Janeiro, 1996.

16. Bachelard, G.; A Filosofia do Não: filosofia do novo espírito científico, Editorial Presença: Lisboa, 1991

17. Mortimer, E.; Investigações em Ensino de Ciências 1996, 1, 1

18. Kominsky, L.; Giordan, M.; Química Nova na Escola 2002, nº 15, 11. 